\title{
Entre mundos: um encontro com o outro na tessitura da narrativa jornalística ${ }^{1}$
}

\author{
Priscila Martins Dionízio
}

\section{Resumo}

0 espaço mediático se constitui como

palco privilegiado de trocas simbólicas e

compartilhamento de sentidos na sociedade

contemporânea. A atividade jornalística, prática

discursiva componente desse espaço, nos coloca

em contato com diferentes povos e culturas,

tecendo narrativas e figuras de alteridade. É para

tais narrativas que nosso trabalho se volta, com 0

objetivo de pensar a relação desenvolvida com a

diferença no processo de produção do jornalismo.

Trabalhamos uma série de reportagens chamada

Nova África, exibida pela TV Brasil, e buscamos

perceber a dinâmica instaurada entre a enunciação

jornalística e a intervenção dos entrevistados,

no processo de constituição de sentidos da série.

Ao olhar para a participação dos entrevistados,

indagamos se o jornalismo consegue acolher as

marcas do outro quando fala sobre ele.

\section{Palavras-Chave}

Alteridade. Jornalismo. Diálogo intercultural.

\section{Priscila Martins Dionízio ।}

primartinsmr@yahoo.com.br

Mestre em Comunicação Social pelo Programa de Pós Graduação em Comunicação e Sociabilidade Contemporânea da Universidade Federal de Minas Gerais (UFMG). Linha de pesquisa: Processos Comunicativos e Práticas Sociais.

\section{Introdução}

No meio de um mar distante, homens tocam a vida cantando. Quem são eles? 0 que pensam? 0 que têm a ver com a gente? Que lugar é esse em que eles vivem? 0 que sabemos sobre essas terras? E o que sabemos sobre esse mundo chamado África?

Esta é a fala de abertura da primeira reportagem da série Nova África, produção brasileira independente, exibida de setembro de 2009 a junho de 2010, pela TV Brasil, emissora da Empresa Brasil de Comunicação e objeto empírico da dissertação de que é fruto este artigo. À fala do narrador, sucedem imagens de homens remando num barco ao mar, cantando em uma língua diferente. Não se sabe, contudo, quem são. É o narrador que nos convida a conhecê-los, conhecer seu mundo. Insinua-se que a construção do conhecimento do mundo do outro será feita a partir do que podemos ter com ele em comum: "0 que têm a ver com a gente?"; e, neste ponto, enunciador e enunciatário se encontram num mesmo plano, marcando a distância de ambos, do universo a ser retratado. Evidenciam-se não três, mas dois polos na 
relação comunicativa: nós e o outro, constituindo o par identidade e diferença.

Pensar esse processo de escritura do outro realizado pelo jornalismo, e mais especificamente pela série de reportagens Nova África, foi a principal indagação que moveu nosso trabalho. 0 que nos interessava perceber era como relatos de viagem e reportagens especiais que trazem o outro como matéria de fascínio e conhecimento podem falar sobre ele, uma vez que são tão distintas as matrizes culturais daquele que narra e daquele que é narrado. Será que tais relatos conseguiriam inscrever a alteridade, trazer vivos o lugar e a palavra do outro?

No caso da série de reportagens analisada, notamos que em seu processo de escritura, havia um gesto semântico que propunha (re)descobrir a África e os africanos através da busca de vozes de seu povo, sugerindo, assim, a construção de uma nova imagem de África que viesse deslocar sentidos eurocêntricos historicamente cristalizados sobre o continente.

Essa motivação por atualizar representações de África existentes em nosso imaginário nos dá indícios do lugar de fala cavado pela série, sinalizando também um entorno contextual mais amplo que abriga e confere pertinência às suas narrativas:

A ocupação da África pelos europeus foi acompanhada de uma 'ofensiva intelectual' que negou a História e a cultura locais. A África foi descrita como um grande vazio, lugar da barbárie e do canibalismo. Aos africanos foi negada a humanidade. Eles eram ora vítimas de outros povos igualmente 'bárbaros', como os árabes, ora agentes da superstição e da maldade. 0 mito do homem negro lascivo e indolente foi socialmente construído para justificar a tomada de terras e a negação de direitos.

Lopes (2008) destaca essa negação da palavra do outro como especificidade histórica do continente africano, ato que ressoa também na recusa de valores que operassem em uma lógica contrária à do 0cidente. De acordo com 0 autor, dentre os valores africanos rejeitados pela "arrogância uniformizadora ocidental" estariam: 0 apagamento do indivíduo face à comunidade, a aceitação e a canalização das paixões pela ritualização, a resistência à acumulação de riquezas, a relação pacífica com o meio ambiente, a recusa à tirania do tempo e a existência de um poder e uma autoridade indivisíveis.

Tal silenciamento da diferença, em tempos de escravismo, colonialismo e agora de capitalismo globalizante, contribuiu para a efetivação de relações antidialogais com o continente ou mesmo com os africanos radicados pelo globo - como no Brasil, país que mais agrega população africana (LOPES, 2008). No caso brasileiro, vive-se uma situação de desigualdade histórica com as populações negras, evidenciada no preconceito arraigado, combatido mais fortemente nos últimos 30 anos por movimentos 
sociais de afirmação, que denunciam o mito da democracia racial e lutam pela institucionalização de políticas públicas voltadas para a diversidade.

Em linhas bastante gerais, este é o cenário que abriga e no qual intervém a série de reportagens Nova África: um espaço-tempo marcado pela desigualdade, exploração e não-escuta do outro. Como qualquer produto cultural, a série de reportagens dialoga com um conjunto de textos disponíveis no imaginário de seus consumidores/ espectadores. Desse modo, temáticas comumente acionadas para situar a África - como a diversidade de fauna e flora, conflitos étnicos, fome, miséria e epidemias - entrecortam as pautas da série de reportagens. Ainda que tais pautas se façam presentes, confirmando, de certa maneira, algumas expectativas sobre 0 continente, há sempre um enquadramento mais largo que direciona as temáticas para um princípio de transformação, de renovação, desenvolvimento e valorização da velha África, vivido e impulsionado por homens e mulheres comuns.

No entanto, o interesse de nosso trabalho, não foi propriamente captar as representações de África geradas pela série de reportagens. 0 que nos ocupava era perceber o processo de construção dessas representações, os mecanismos de constituição de sentidos das narrativas, bem como as dinâmicas das interações desenvolvidas com os africanos entrevistados na tessitura da série, tentando perscrutar um possível deslocamento do quadro histórico de não-escuta do continente negro.
É para esse processo de fabricação de relatos do outro, no universo midiático, que buscamos atentar, entendendo que eles engendram a possibilidade de reproduzir e atualizar estruturas de pensamento, bem como têm impregnada em seu processo de escritura a conflituosa relação de ser com a diferença. Por fim, vale dizer que nosso estudo foi guiado pela inquietação, sempre em suspenso: ao falar sobre o outro, o jornalismo consegue também falar com esse outro?

\section{0 texto que fabrica o outro}

Se investirmos nos caminhos dos relatos de viajantes, em tempos de colonização, encontraremos nos campos da literatura, da história e ciências naturais um notável processo de invenção das alteridades meso-americana e oriental, por exemplo.

Edward Said é um dos autores que se debruça sobre tais relatos - bem como imagens, documentos e pronunciamentos políticos buscando a constituição de um imaginário ocidental acerca do Oriente. 0 conjunto de ideias aglutinadas por exploradores e viajantes sobre o então desconhecido mundo a leste da Europa, Said (1990, p. 13-14) denomina orientalismo:

[noção que diz de] um modo de resolver o Oriente que está baseado no lugar especial ocupado pelo Oriente na experiência ocidental europeia. 0 Oriente não está apenas adjacente à Europa; é também onde estão localizadas as maiores, mais ricas e mais antigas colônias européias, a fonte das suas civilizações e línguas, seu concorrente 
cultural e uma das suas mais profundas e recorrentes imagens do Outro. Além disso, o Oriente ajudou a definir a Europa (ou o Ocidente) como sua imagem, ideia, personalidade e experiência de contraste. [...] 0 Oriente é parte integrante da civilização e da cultura materiais da Europa.

0 autor enfatiza o orientalismo como discurso de dominação sobre 0 Oriente, erigido a partir de uma consciência europeia soberana. A princípio, tal discurso seria regido por ideias gerais sobre o que e quem era 0 oriental; em um segundo momento, funcionaria de acordo com uma lógica governada pela realidade da colonização, bem como pelo conjunto de desejos, repressões e projeções do Ocidente. Said (1990, p. 103) levanta a importância de se pensar 0 orientalismo, não como uma conspiração imperialista ocidental, mas como uma cristalização de consciência geopolítica em textos de ordem estética, social, econômica e histórica:

[...] tais textos podem criar, não apenas o conhecimento, mas também a própria realidade que parecem descrever. Com o tempo, esse conhecimento e essa realidade produzem uma tradição, ou o que Michel Foucault chama de discurso, cuja presença ou peso material, e não a autoridade de um dado autor, é realmente responsável pelos textos a que dá origem.

Said pensa o orientalismo como um sistema, no qual um discurso remete a outro e atualiza um outro, na constituição de um imaginário, de um conjunto de representações. Tal construção discursiva, desenvolvida fora e para fora do Oriente, teria sido responsável pela designação geográfica, moral e cultural dos povos de lá.
0 cerzimento de imagens e textos, de ficção ou não, alavancou um lento processo de construção da alteridade oriental no 0cidente. 0 que nos interessa perceber nesse quadro é a produção da alteridade através de fragmentos discursivos externos, de outro tipo de sociedade, que acabaram por constituir um imaginário extremamente etnocêntrico sobre 0 Oriente, esculpindo sentidos sobre seu silêncio.

Henrique Carneiro (2001) considera essas primeiras descrições de terras desconhecidas, os relatos de viagem, não apenas um gênero literário, mas científico, político, econômico e moral. De acordo com 0 autor, tais textos acabaram por se firmar como fontes primárias que documentaram visões de época, trazendo testemunhos e imagens coloniais-colonizadoras, produzidas a partir das impressões do narrador.

No caso do Brasil, os relatos de viajantes representaram papel capital na constituição de um imaginário sobre a terra nova, não só em Portugal e na Europa, mas também internamente. Tais relatos foram as fontes primárias mais significativas sobre o país até o século XIX, quando 0 romantismo chega à nossa produção literária, dando início a uma volta às origens, em busca de uma (re)fabricação da identidade nacional (SÜSSEKIND, 1990; BATISTA, 2009).

Cartas e documentos sobre a experiência na colônia foram deixados por viajantes europeus que estiveram no Brasil, nos séculos XV e XVI, 
dentre eles os religiosos Manuel de Nóbrega e José de Anchieta, e os viajantes-exploradores como 0 português Pero Gândavo, o alemão Hans Staden e os franceses André Thevet e Jean de Léry. Em diálogo com os relatos de Léry sobre o Brasil, Michel de Certeau (2000, p. 215) indaga sobre a palavra que se institui no lugar do outro:

Em 1556, Jean de Léry tem 24 anos. Sua Histoire, vinte anos mais tarde, dá uma forma circular ao movimento que ia de cima (ici, a França) para baixo (là-bas, os Tupi). Transforma a viagem em um ciclo. Traz de là-bas, como objeto literário, o selvagem que permite retornar ao ponto de partida. 0 relato produz um retorno de si para si, pela mediação do outro. Mas alguma coisa que escapa do texto permanece là-bas: a palavra tupi. Ela é aquilo que, do outro, não é recuperável - um ato perecível que a escrita não pode falar.

Tal relação escriturária com 0 mundo, nos termos de Certeau, é efeito de um saber que pisa e varre ocularmente a terra para construir, de maneira vertical, um conjunto de representações sobre ela.

Podemos perceber esse mesmo gesto textual quando da colonização brasileira relatos transformavam os indígenas em objetos naturais. Em História da Província de Santa Cruz, Pero de Magalhães de Gândavo, descreve, nos primeiros capítulos, as qualidades da terra, a divisão das capitanias, como vive a gente portuguesa que estava aqui, os alimentos e frutas, os animais, um possível monstro marinho morto na capitania de São Vicente e, somente no décimo capítulo Gândavo (2004, p. 133) diz "Do gentio que há nesta província, da condição e costumes dele, e de como se governam na paz". E continua:

Estes índios são de cor baça e cabelo corredio; têm 0 rosto amassado e algumas feições dele à maneira de Chins. Pela maior parte são bem dispostos, rijos e de boa estatura; gente muito esforçada e que estima pouco morrer; temerária na guerra e de muito pouco consideração. São desagradecidos em grande maneira e muito desumanos e cruéis, inclinados a pelejar e vingativos por extremo. Vivem todos nus, descansados, sem terem outros pensamentos senão de comer, beber e matar gente e, por isso, engordam muito, mas com qualquer desgosto pelo conseguinte tornam a emagrecer e, muitas vezes, pode deles tanto a imaginação que se algum deseja a morte ou alguém lhe mete em cabeça que há de morrer tal dia ou tal noite não passa daquele termo que não morra. [...] São muito desonestos e dados à sensualidade, e assim se entregam aos vícios como se neles não houvera razão de homens [...] (GÂNDAVO, 2004, p. 134-135).

Neste breve relato, podemos notar que uma força discursiva conjuga-se a um lugar de autoridade ocupado pelo narrador: observador atento e imparcial. Miriam Leite destaca uma possível posição de vantagem do narrador de viagens por ser ele alguém "de fora" e estar ali "de passagem" (LEITE, 1997 apud CORREA, 2005, p. 5). De acordo com a autora, por não precisar ser aceito pelo grupo, o viajante legitima um lugar seguro e coletivamente entendido como neutro, para a produção de seu relato. Sob o olhar que se apresenta objetivamente descritivo, fica obscurecida uma possível retórica de produção da alteridade que oblitera os obstáculos enfrentados pelo narrador/ viajante para compreender o mundo do outro, bem 
como os impasses linguísticos e culturais vividos para inscrever a diferença em texto.

Nosso movimento em direção aos relatos de viagem busca perscrutar aproximações do gesto textual dos viajantes com 0 gesto empreendido por narrativas jornalísticas contemporâneas que se lançam à representação de povos outros e diferentes formas de ser que habitam 0 mundo. Não mais com 0 intuito colonizador ou desbravador de terras e povos nunca antes conhecidos, mas com um apelo por vezes turístico, e com uma forma que se aproxima em muito dos diários de viagem, as narrativas do jornalismo ocupam o espaço midiático fabricando diversas figuras de outridade. Podemos perceber nelas uma retórica próxima à dos viajantes, com a presença do narradortestemunha, a ferramenta da descrição aparentemente objetiva, uma motivação por compreender e elucidar formas de vida, bem como resquícios identitários que perpassam a construção de sentidos.

Ao pensar o processo de escritura do outro, percebemos que o espaço do texto é, ele próprio, lugar primordial da fabricação da alteridade.

Eric Landowski (2002) nos diz que a diferença se constitui através de uma operação semântica, não podendo ser considerada como algo já dado no mundo. Fazer existir o outro é situá-lo num espaço-tempo, conseguindo, através desta operação, efeitos de sentido que possam permitir apreender a diferença objetivada:
[...] com a condição de relativizar meu 'ser', isto é, de descobrir o ser do outro, ou sua presença ou de me descobrir eu mesmo parcialmente outro, eu faço nascer o espaço-tempo, como suporte de diferenças posicionais entre mim mesmo e meus semelhantes, como efeito de sentido induzido pela distância que percebo entre meu aqui-agora e todo o resto - lugares distantes, tempos distintos - ou ainda como resultante da relação que me liga, eu sujeito, a um mundo objeto cujas formas discretas, à medida que as recorto, me revelam a mim mesmo (LANDOWSKI, 2002, p. 68).

0 autor ressalta também o jogo sempre subjacente que se instaura entre um e outro: na medida em que estabeleço distâncias para marcar o lugar do outro, evidencio meu próprio estar no mundo. São, pois, esses processos, ou procedimentos, de espacialização e temporalização que permitiriam aceder e enunciar 0 significado de outrem. Ao pensar as narrativas de viagem, Landowski (2002) atenta para o processo de construção de cenários que envolve o próprio regime de identidade dos sujeitos que narram, na medida em que as variáveis espaço-temporais se mobiliam em torno de sua figura, segundo sua lógica própria. Dessa maneira, o autor apresenta um entendimento de que espaço, tempo e alteridade não são categorias existentes a priori: há apenas sujeitos que, ao edificarem um "aqui-agora", constroem as condições de relação consigo mesmo, em que localizam o próprio mundo como alteridade presente.

Nessa diretiva, as contribuições de François Hartog (1999), ao sistematizar o processo de produção retórica da alteridade, na matriz narrativa grega, 
mais especificamente do historiador Heródoto, também nos ofereceram pistas acerca da operacionalização do ritual de produção de sentido e escritura sobre 0 outro. 0 autor nos diz de uma relação tríadica que envolve um narrador, que expõe um mundo de outrem, a um segundo interlocutor. 0 narrador é, então, responsável por transpor o mundo que se conta ao mundo em que se conta e o processo de transposição de mundos se faria por meio de ferramentas de tradução, como a comparação, a descrição e a inversão: "[...] uma retórica da alteridade é, no fundo, uma operação de tradução: visa a transportar o outro ao mesmo (tradere) - constituindo, portanto, uma espécie de transportador da diferença." (HARTOG, 1999, p. 251).

Para 0 autor, só é possível inscrever o inimaginável e o desconhecido através de um processo de tradução que confere ares de familiaridade à diferença:

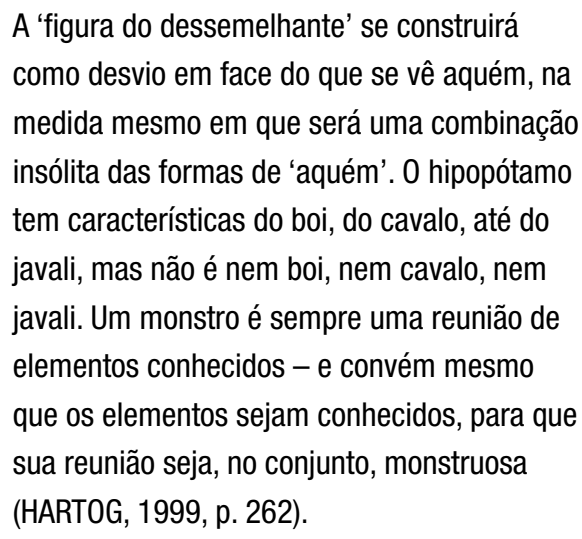

Embora Hartog nos fale especificamente dos traços da matriz narrativa de Heródoto, Silva e Mello (2002) atenta para possíveis aproximações entre 0 gesto narrativo empreendido pelo historiador e as formas de narrar que perpetuaram no ocidente, incidindo também sobre as narrativas do jornalismo. Nessa perspectiva, nos permitimos lançar algumas provocações: estabelecer correspondências, avaliar, medir, atribuir um espaço-tempo do próprio ao universo do outro permitiria mesmo compartilhar com ele perspectivas, compreendê-lo para enunciá-lo? A que estratégias discursivas se recorre quando não se pode comparar, descrever por aproximação, opor? Se alguma face do outro não encontra correspondência de sentidos no mundo do um, como percebê-la, comunicá-la? E, por fim: a figura do outro, a possibilidade de acessão a seu universo de referências e sua inscrição estão colocados como inquietações para 0 campo do jornalismo?

\section{As fragilidades do encontro}

Para pensar a inscrição da diferença no universo do jornalismo, parece-nos necessário situar a questão no âmbito de uma práxis, pois carente é 0 campo de estudos, no que diz respeito à tematização da alteridade, e frágeis são o encontro intercultural e as formas enunciativas de que a prática jornalística dispõe para dizer o outro.

Alsina e Morna (2001) e Alsina (2003), ao pensar a comunicação intercultural, ressalta uma conjunção de forças que perpassam a criação de textos jornalísticos impregnados de estereótipos simplificadores e identidades estigmatizadas: primeiramente uma lacuna no ensino, que não 
prioriza o estudo do diálogo intercultural; já no que diz respeito à prática da profissão, as restrições destacadas pelo autor são as limitações à produção discursiva impostas pelo sistema produtivo do jornalismo - 0 acelerado tempo da produção informativa, 0 texto extremamente conciso e a clareza imperativa na codificação da mensagem, ou seja, na tradução do outro, para o espectador.

Ao tocar na tríade comunicativa que sustenta a enunciação jornalística (a imagem de quem fala, aquele de quem se fala e 0 destinatário do discurso), Alsina (2003) nos permite atentar para primazia do espectador no processo de produção de sentidos da comunicação intercultural. A ênfase no espectador traz a necessidade de explicar para ele quem é o entrevistado, ou o que é uma dada situação, uma vez que estes últimos não podem entrar na narrativa como uma incógnita.

Neste jornalismo de que nos fala 0 autor, a relação comunicativa com o entrevistado parece ser travada com vias à elucidação - dele mesmo ou de uma situação -, e ainda que não fosse feita propriamente uma tradução, mas uma invenção do outro, como clamado por Roy Wagner (2010), os mecanismos de invenção de que disporia 0 jornalismo seriam cerceados pela necessidade de uma clareza linguística e da elaboração de um sentido mais facilmente apreendido, ou hegemônico, que dialogue com uma maior diversidade de públicos. Por essa razão, Alsina e Morna (2001) nos dizem que o outro acaba por ser humanizado, personalizado pelas narrativas, tendo destacadas as diferenças e as semelhanças mais universais dele com a cultura que 0 enuncia; ou, então, este outro é convertido em uma abstração, em um coletivo indiferenciado e cristalizado em um estereótipo.

Demais trabalhos que centralizam a inscrição do outro como inquietação buscam pensar a potencialização do diálogo por meio da entrevista (MORIN, 1973; MEDINA, 2002); entrelaçam técnicas da entrevista em História Oral com a entrevista jornalística (MAIA, 2006; ROÜCHOU, 2003; SANTHIAGO, 2007); e apresentam contribuições através da problematização da linguagem e da gramática textual do jornalismo, com suas fragilidades e limites na inscrição da diferença (RESENDE, 2002, 2009). Ao apontar que o jornalismo trabalha a diferença como simples abstração, Lago (2010) sugere uma incorporação do saber antropológico no campo do jornalismo, por este último carecer de ferramentas que consigam apreender e acolher o outro em suas narrativas. Tais trabalhos formam um pequeno coro que busca tematizar a operação de construção da alteridade na narrativa jornalística, apontando também a necessidade dos estudos em jornalismo se ocuparem da reflexão sobre a relação com 0 outro representado.

A partir da contribuição de tais autores, na construção do problema de nosso estudo, buscamos pensar também que a conturbada relação com a diferença no processo de construção de sentidos do jornalismo é enraizada na própria dinâmica da vida social. 
Através da comunicação, experienciamos o mundo e 0 organizamos de modo a vivêlo em comum, construímos sentidos, nos ligamos ao outro, nos constituímos como sujeitos. A comunicação se nos mostra como lugar de movimento, de encontro, de transações dinâmicas, partilha e negociação de ideias, valores, afetos. Constituindo-se como esse espaço do movimento, as práticas comunicativas participam também do lento processo de sedimentação e cristalização dos sentidos, tecendo discursos e representações que orientam o curso da vida em sociedade. Dessa maneira, pela comunicação também são reproduzidos sistemas de ideias, ideologias são materializadas e perpetuadas, relações de força mantidas, consensos e padrões hegemônicos constantemente recriados.

E em meio a essa mobilidade de sentidos amalgamadora da vida social, figuras de alteridade são cristalizadas na face do estrangeiro, do marginal, do desviante, do desconhecido. A alteridade parece, contudo, necessária para que se possa dizer eu sou. Dizer que sou este e não aquele me permite traçar uma linha fronteiriça entre eu e o outro, na configuração de um processo relacional de demarcação e constituição de identidades e outridades. É, então, através de um processo de diferenciação que a unidade parece se constituir. 0 par identidade/diferença se revela indissociável, na medida em que 0 outro, ainda que calado, à sombra, ou em seu reverso, habita a figura do um.
Entendendo a fabricação das alteridades como essa relação constitutiva, Eric Landowski (2002) ressalta que para chegarmos, nós mesmos, a uma existência semiótica temos sempre a necessidade de um eles. Estabelecida a fronteira entre nós e eles, nos constituiríamos por diferenciação, na medida em que efetuamos operações de objetivação da alteridade, atribuindo-lhe um conteúdo específico:

[0 outro] é também 0 termo que falta, 0 complemento indispensável e inacessível, aquele imaginário ou real, cuja evocação cria em nós a sensação de uma incompletude, ou o impulso de um desejo, porque sua não-presença atual nos mantém em suspenso e como que inacabados, na espera de nós mesmos. (LANDOWSKI, 2002, p. XII).

0 outro se interpõe, pois, como um eco que nos habita e a partir do qual nossa existência - ou a apreensão de nós mesmos como sujeitos no mundo - torna-se possível. "Assim que tento definir-me para mim mesmo [...] encontro a mim mesmo apenas nele, nesse mundo antedado, fora da minha já-presença temporal." (BAKHTIN, 2003, p. 112). A apreensão-definição do outro e de nós mesmos só, então, ganha corpo ao estabelecermos vínculos e relações; no processo de interação, mediado e realizado pela linguagem, os sujeitos se constituem um para 0 outro, marcam lugares e organizam sentidos.

0 plasmar sentidos em comum, contudo, não implica em relações simétricas ou livres de conflito entre um e outro; e é a própria assimetria das relações que nos 
incita a pensar a problemática das sociabilidades. No desenvolvimento da dissertação foi o conceito de enquadramento que nos ajudou a compreender e desdobrar as fases da relação comunicativa, processo em que um se faz para o outro e em que os sentidos são apreendidos, interpostos.

Ao apresentar sua noção de enquadre, Gregory Bateson $(1981,2002)$ nos diz que ela corresponde ao conjunto de instruções para que um interlocutor seja capaz de compreender a situação comunicativa bem como o conteúdo da conversa que está sendo construído. 0 enquadre seria uma espécie de moldura que delimita ou dá pistas aos interlocutores a respeito do que devem observar, enfatizar, trazer a primeiro plano, e como devem se posicionar em uma relação. Bateson (1981) pontua que as relações comunicativas trazem premissas subjacentes que atuam na configuração dos quadros - podemos ressaltar aqui as referências culturais dos interlocutores. Apesar de flexíveis, e de serem construídos na relação com o outro, os quadros são constituídos pelo repertório cultural mais ou menos compartilhado dos interlocutores e pelo contexto que eles acionam e, ao mesmo tempo, ajudam a constituir.

Através dos quadros de sentido, recortamos e organizamos o mundo e nossa experiência nele. Tanto para o Bateson (1981), quanto para Goffman $(1974,1999)$ - autor que trabalha futura e extensamente a noção de enquadre, conferindo a ela 0 nome de frame -

o quadro opera em um nível metacomunicativo que "enforma" o conteúdo das mensagens e a própria interação. Como operador de organização da experiência, o quadro age no reconhecimento que se tem tanto da situação de fala, quanto do parceiro de interlocução, o outro.

Em nosso percurso de análise, atentamos para essa conjugação de quadros nos momentos de entrevista da série Nova África, buscando perceber a leitura que repórter e fonte faziam um do outro, bem como dos temas em debate, com 0 intuito de entender melhor e problematizar a relação identidade e diferença, no processo de constituição de sentidos da série.

Desse modo, o movimento do olhar desenvolvido em nosso trabalho buscava situar a problemática da relação com a diferença de maneira mais ampla, no seio da vida social, passando, então, a um olhar mais específico dirigido às formas dizer e aos processos de produção de sentido no universo do jornalismo e na série de reportagens Nova África.

\section{Esboço metodológico e recorte empírico}

Nosso estudo se guiou por uma questão que, de modo mais geral, indaga: como o jornalismo fala do outro? Para explorar esse questionamento, dentro da série Nova África, traçamos cinco eixos que buscaram mapear: 
1. 0 processo de presentificação da alteridade, apontado por Landowski (2002), como dinâmica através da qual se faz existir o outro, conferindo a ele uma espacialidade e uma temporalidade. Através do esboço de linhas de espaço e tempo, a reportagem consegue objetivar o mundo do outro, identificá-lo e comunicá-lo. Atentar para esse processo pode nos permitir perceber também um conjunto de representações e leituras de mundo compartilhadas com o receptor/destinatário, que direcionam a construção semântica do africano;

\section{As passagens de elucidação do outro -} traços característicos da reportagem - que para tornarem a diferença comunicável, podem lançar mão de ferramentas de tradução, como as elencadas por Hartog (1999), quais sejam: a inversão, a comparação e a descrição. Eliseo Verón (2004) nos chama atenção para as modalidades e modos de dizer que dão forma ao que ele chama de dispositivo de enunciação. Tal dispositivo comporta a tríade envolvida na relação comunicativa: a imagem de quem fala, a relação deste que fala com o que ou quem ele diz, bem como a imagem daquele a quem o discurso é endereçado. Pensar o processo de elucidação do outro, considerando a tríade comunicativa, nos permitiria apreender 0 embate entre os universos culturais do um que enuncia e do outro que é enunciado. Mais um ponto-chave que poderemos observar aqui é a figura do enunciador uma jovem repórter, negra, chamada Aline Midlej. A série Nova África apresenta diferentes estratégias enunciativas: ora se tem a repórter como narradorpersonagem, comandando o processo de produção de sentidos, com suas vivências e impressões; ora observamos um recuo do enunciador em favor da voz dos entrevistados. Dessa maneira, nos interessaria notar como a repórter se relaciona com os eventos: se ela os interpreta e avalia, se ela os relata com distanciamento, se é permitido aos entrevistados que instituam sentidos sobre as situações elucidadas.

\section{A organização de perspectivas nos momentos} de entrevista que busca perceber os elementos trazidos a primeiro plano na relação comunicativa pela repórter e por seus entrevistados. Nesse momento, podemos atentar para os possíveis quadros de sentido mobilizados pelos interlocutores na leitura de uma dada situação;

\section{0 lugar ocupado pelo outro, operador que} nos ajuda a identificar como se inserem as falas dos entrevistados/as e o lugar ocupado/conferido a eles/as na totalidade de cada reportagem.

Perscrutamos se a fala do outro é complementar, ilustrativa ou agrega o potencial de fundar novos sentidos nas narrativas;

\section{Enquadramento, por fim, buscamos notar,} através dos pontos recortados nos eixos anteriores, a constituição relacional de modos de inteligibilidade do outro, ou seja, os possíveis enquadres que mais sobressaem nas reportagens. 0 processo de presentificação, as passagens de elucidação e a organização de perspectivas, realizada por repórter e fonte nos momentos de entrevista, nos deixam pequenos indícios que vão participar da constituição de um quadro maior de leitura do continente e 
do povo africano. É, então, para essa junção de pontos na constituição de um quadro maior que nos propusemos atentar.

No conjunto das 32 reportagens que compõem a série Nova África, recortamos seis delas para composição de nosso corpus. Primeiramente, agrupamos reportagens que abordassem países falantes da língua portuguesa, de modo que pudéssemos explorar melhor as entrevistas, por serem menos editadas e sem dublagens. Selecionamos, então, quatro das reportagens feitas em países lusófonos: 0 bloco sobre Moçambique - 01, 02, 03 - e a reportagem 29 sobre os estilos musicais de Cabo Verde.

Em um segundo momento de delimitação, pensamos em agrupar reportagens que tratassem de modos de vida bastante tradicionais, de matrizes culturais claramente distintas das do enunciador e do destinatário, buscando perceber como se dá a produção de sentidos sobre 0 outro nessas situações. Com essa diretiva, selecionamos a reportagem 09 sobre os Pigmeus e os Povos San.

Para, por fim, fechar nosso corpus, pontuamos a última reportagem, 32, por apresentar um balanço das reportagens anteriores e uma síntese do que seria essa nova África apresentada pela série.

\section{Análise-síntese}

A tentativa de tecer considerações gerais sobre a série Nova África, e, até mesmo, sobre nosso objeto de conhecimento, nos intimida com 0 risco, sempre presente, de sintetizá-los arbitrária e categoricamente. Vamos passar por alguns achados da pesquisa, entendendo que talvez eles revelem muito mais um caminho de indagação que propriamente respostas claras.

Em algumas reportagens da série Nova África, percebemos que o esboço de linhas esaçotemporais, para a identificação do outro, aciona um contexto que dialoga com um universo de representações disponível nos imaginários do enunciador e enunciatário ou ainda temporalidades e espacialidades extraídas do tempo da viagem, da chegada da equipe de reportagem nas localidades nessa última situação, o liame que garante coesão à narrativa é muito mais 0 estar em trânsito e a figura da viajante.

Essa presentificação artificializada do outro, por assim dizer, pode ser percebida também na convocação de temáticas que vêm a situar a diferença. A reportagem 02, produzida no interior de Moçambique, é bastante característica nesse sentido; ao tratar da malária, da aids e da prostituição, a narrativa mobiliza um conjunto de temas possivelmente compartilhados com o espectador na identificação do africano/moçambicano, mostrando-se pouco porosa à instituição do espaço, do tempo e das tematizações possivelmente levantadas pelo outro. Em contraposição, a reportagem 29, Sons de Cabo Verde, também se utiliza do procedimento de 
presentificar o outro através da apresentação de uma temática - os vários estilos musicais - conseguindo, contudo, inscrever o caboverdiano e suas subjetividades, com a escuta de várias vozes e com 0 recuo das impressões pessoais da repórter e do tom elucidativo da reportagem, a qual não se ocupou em familiarizar e racionalizar a diferença.

As passagens de elucidação do outro conjugadas ao posicionamento da repórter são pontos que nos instigaram para a problematização do diálogo intercultural. Pudemos mapear três diferentes posicionamentos da repórter, cada um com suas implicações na relação com o outro e com a apresentação/elucidação da diferença. Em algumas narrativas, a repórter situa 0 outro apresentando 0 que vê pelo caminho; noutras, a voz da repórter é ainda presente na determinação dos sentidos, mas como voz over; e há reportagens, ou trechos delas, em que a repórter faz um recuo na enunciação, deslocando-se de uma posição de voz privilegiada.

Quando a repórter narra o que encontra e percebe durante a viagem, vimos que se abrem duas possibilidades de construção semântica: de um lado, assistimos à transformação do enunciador em narrador-testemunha, como nos relatos de viajantes, exercendo uma força centrípeta sobre o processo de organização de sentidos, uma vez que ele se torna o centro de onde irradiarão os significados - ou as impressões transformadas em significados. De outro lado, vimos uma possibilidade de entrega à construção local do contexto e das situações que abrigam o outro, abrindo a reportagem a acontecimentos inesperados e à potencial intervenção dos entrevistados. Percebemos que a primeira alternativa é a mais frequente nesses momentos de filmagem um pouco mais livre, em que a repórter se coloca a vagar por vilarejos e cidades, lançando suas impressões-descrições dos lugares e ora de práticas culturais de um povo:

Repórter: Gente, olha, minha primeira impressão é maravilhosa, a gente chegou na vila onde os pigmeus tão morando no momento. São várias famílias, crianças, mulheres... Olha só, tem gente cozinhando ali, fazendo a fogueira, olha tão cozinhando a mandioca, tá descascando ali, eu acho que já é pro jantar. Bom, acho que a hora é boa, tá todo mundo cozinhando, a gente vai poder encher a barriga hoje, pelo jeito. (Reportagem 9 - Pigmeus).

Noutra reportagem, ao passar por um vilarejo não identificado, no interior de Moçambique, relatando o momento de lazer de seus moradores, a repórter apresenta brincadeiras e uma barbearia comandada por um jovem de 15 anos. Ao falar do futebol jogado pelas crianças, um morador tenta engajar em interação com a repórter, mas não é acolhido: enquanto ela descreve uma bola feita de trapos, o homem completa com algumas palavras, mas não ganha espaço de fala. Dessa maneira, o enunciador completa com suas impressões pessoais, sem a voz do outro; mais uma categorização fugaz: "Há, nesta região de Moçambique, uma certa ingenuidade. [...]. Essa criatividade das 
crianças moçambicanas é a mesma que rola nos campinhos e ruas de terra do Brasil."

Todavia, pudemos notar as marcas deixadas pelo outro, frente a essa postura da repórter, em algumas das narrativas: na terceira reportagem, por exemplo, fala-se do Grande Hotel de Maputo, mas quem apresenta 0 Grande Hotel são seus moradores, junto ao vagar da viajante; na primeira reportagem, vemos a tetraneta de Tomás Antônio Gonzaga quebrar o tom lírico que imperava na narrativa ao falar do poeta. Num primeiro momento, a entrevistada descreve como foi a vida dele em exílio, posição a que possivelmente foi convidada a falar, e, em seguida, lança uma dúvida que a incomoda, conseguindo abrir um lugar de fala que ultrapassa o posicionamento inicialmente lhe conferido:

Onde viveu Tomás Antônio Gonzaga? Esta é a dúvida que eu gostaria de ser explicada. Dos registros que temos acesso, apenas diz que ele viveu na Rua da Saúde, que é esta em que nós estamos. [...]. Deve ser investigado pelos historiadores moçambicanos a história de cada casa. Todas as casas aqui têm a sua história. Aqui era também um centro de escravos. As cavas das casas junto ao mar também eram ali onde os senhores de escravos punham os escravos antes de os vender. Então, essa história devia estar identificada nas casas! (Reportagem 1).

Nas narrativas em que a repórter se desloca do centro do processo de produção de sentidos, observamos um empoderamento das falas dos entrevistados. Na verdade, fica difícil dizer se 0 poder de fala dos entrevistados, com a instituição de temáticas e a ampliação de sentidos, é o que provoca o recuo do enunciador ou se é o recuo do enunciador que propicia a inscrição do outro nas reportagens. A terceira e a $29^{\mathrm{a}}$ reportagens são as mais expressivas nesse sentido; ao falar de suas artes e produções musicais, as fontes lançaram também temas como conflitos políticos, opressões de gênero e a forma de sentir e se relacionar com os sons de suas terras.

Apreender os diferentes posicionamentos do enunciador, em cada reportagem, nos permitiu atentar para o espaço conferido ao outro para a elaboração de uma imagem de si mesmo e, neste seio, para os quadros de sentidos mobilizados para a leitura das diversas situações apresentadas. Quando as fontes tinham instrumentos, como competência linguística, um bom desempenho frente à câmera e um universo de representações mais amplamente compartilhado com a reportagem, pareciam participar com mais equilíbrio do processo de negociação de entendimentos e configuração de um quadro de inteligibilidade para ler seu povo e seu país. Do contrário, a reportagem acabava por falar pelo outro na maior parte do tempo, através de impressões do enunciador ou da objetificação dos sujeitos narrados que se tornavam uma turva abstração do africano ou de um povo específico (moçambicanos, pigmeus, san).

Essa generalização do outro se refletiu na nãoidentificação de alguns entrevistados/as e mesmo no não-investimento das reportagens em temas 
mais espinhosos, ou conflituosos, ressaltados por eles nos momentos de entrevista. Em meio à leitura de poesias e sobe-sons de músicas tradicionais, escapou de falar da Luta pela Libertação Nacional de Moçambique, da fome manifestada por pescadores moçambicanos, dos anseios dos san, que vivem resguardados em uma área demarcada, das influências urbanas nas comunidades Mbut - temas e leituras acionadas pelas fontes nos momentos de entrevista que, contudo, não foram desenvolvidos/aprofundados no curso das interações.

Com a estreita superfície de contato desenvolvida, a percepção do outro ficou restrita, em muitos momentos, ao reconhecimento de familiaridades, do que tem a África em comum com o Brasil; tal reconhecimento de familiaridades potencializou o estabelecimento de um grande quadro de leitura: os africanos são parte de nossa parentela. Desse movimento, pudemos perscrutar dois grandes critérios de relevância para se enxergar a África, que vieram a se transformar em dois fortes enquadramentos: 0 impulso ao novo, 0 desenvolvimento e reconstrução dos países africanos pós-colonização, enfatizando a luta dos homens e mulheres comuns - ainda que muitas reportagens transformassem esses sujeitos em personagens sem uma face clara -; e a proximidade das culturas brasileira e africana.

As representações que emergem da escritura da Nova África, contudo, não calam absolutamente o outro: vimos momentos em que os entrevistados desafiam saberes constituídos do enunciador, quebram possíveis expectativas da produção jornalística, abrem lugares de fala elaborando discursos de reivindicação e justificação das situações vividas por eles, instituem sentidos que não são racionalizados pelas narrativas. Mas percebemos que as vozes dos africanos se fazem ouvir quando eles não se deixam calar. 0s processos de produção do jornalismo parecem não estar preparados para acolher as marcas do outro e seus lugares de fala quando ele não consegue investir sozinho na marcação de seu lugar. A relação criada com os entrevistados, com o objetivo principal de explicá-los, interpretálos, avaliar suas condições de vida, e mesmo a construção narrativa através da experiência da viagem vivida pelo enunciador, suspeitamos, não facilitarem a expressão da diferença ou a construção conjunta de sua imagem.

Se a série Nova África não consegue trazer seus sujeitos narrados para 0 centro das reportagens e tecer sentidos em conjunto com eles, pensamos que esse impasse pode decorrer da conjugação de fatores que não se dissociam: em primeiro lugar, da fragilidade do encontro cultural, em seguida, da insuficiência dos princípios organizadores de sentido de nossas formas jornalísticas, que limitam, inclusive, as potencialidades do audiovisual na reinvenção de caminhos que propiciem trazer viva a palavra do outro, por meio de outras formas de interação que acolham a expressão dos sujeitos. 0 que fica evidente para nós é o desafio do diálogo 
intercultural - colocado ao jornalismo e também à sociedade contemporânea.

Centralizar a interação como lócus primordial de produção de sentido sobre/com a diferença nos parece ser um caminho para pensar a reportagem/ escritura jornalística. Dessa maneira, a narrativa, nascida do encontro, do choque de diferenças, do entre-lugar criado por um e outro se transformaria - ao passo que se daria a ver - em um mundo não-antedado, um mundo somente existente entre, somente em relação.

\section{Referências}

ALSINA, Rodrigo Miquel; MORNA, Catalina Gaya. Medios de comunicación e interculturalidad.

Cuadernos de Información. n. 14, p. 105-110, 2001. Disponível em: < dialnet.unirioja.es/servlet/fichero_arti culo? codig $0=2938112 \&$ orden $=0>$. Acesso em: 10 dez. 2012.

ALSINA, Rodrigo Miquel. Reflexiones sobre la comunicación intercultural. In: SEMINÁRIO VIRTUAL REALIDADE MULTILINGÜE Y DESAFIO INTERCULTURAL, 2003, Peru. Anais... Peru: Pontificia Universidad Católica del Peru, 2003. Disponível em: < http://red.pucp.edu.pe/ridei/ buscador/files/inter33.PDF $>$. Acesso em: 10 dez. 2012.

AZENHA, Luiz Carlos. Série Nova África. 2009. Anteriormente disponível em: < http://tvbrasil.ebc. com.br/novaafrica/category/diario-de-bordo/page/2/> . Acesso em: 10 abr. 2011.

BAKHTIN, Mikhail. 0 todo temporal da personagem: a questão do homem interior - da alma. In:

Estética da criação verbal. 2. ed. São Paulo: Martins Fontes, 2003. p. 91-126.
BATESON, G. Communication. In: WINKIN, Yves (Org.). La nouvelle communication. Paris: Éditions du Seuil, 1981. p. 115-144 (Points essais, n. 136). . Uma teoria sobre brincadeira e fantasia. In: RIBEIR0, Branca Telles.; GARCEZ, Pedro M.. (Org.). Sociolinguística interacional. São Paulo: Loyola, 2002. p.85-105.

BATISTA, Eduardo L. A. 0. Literatura de viagem e tradução literária como criadores de imagens culturais: um estudo de sua influência no desenvolvimento da história cultural brasileira. Revista brasileira de tradutores, n. 18, p. 119-130, 2009,. Disponível em: < http://sare.unianhanguera. edu.br/index.php/rtcom/article/viewFile/1019/652> . Acesso em: 10 abr. 2011.

CARNEIR0, Henrique S. 0 múltiplo imaginário das viagens modernas: ciência, literatura e turismo. História: questões \& debates. Curitiba, n. 35, p. 227-247, 2001 . Disponível em: < ojs.c3sl.ufpr.br/ojs2/index.php/historia/ article/download/2681/2218> . Acesso em: 10 abr. 2011.

CERTEAU, Michel. A operação historiográfica. In: . A escrita da História. Rio de Janeiro: Forense-Universitária, 2000. p. 65-108. . Etno-Grafia: a oralidade ou o espaço do outro: Léry. In: . A escrita da História. Rio de Janeiro: Forense-Universitária, 2000, p. 211-265.

CORREA, Silvio M. S. Narrativas sobre o Brasil alemão ou a Alemanha brasileira: etnicidade e alteridade por meio da literatura de viagem. Anos 90. Porto Alegre, v. 12, n. 21-22, p. 227-269, jan./dez., 2005. Disponível em: seer.ufrgs.br/anos90/article/download/6375/3823. Acesso em: 10 dez. 2012.

GÂNDAVO, Pero de Magalhães de. A primeira história do Brasil: história da província Santa Cruz a que vulgarmente chamamos Brasil. Modernizado do texto original de 1576 e notas, Sheila Moura Rue, Ronaldo Menegaz; revisão das notas botânicas e zoológicas: Ângelo Augusto dos Santos; prefácio: Cleonice Berardinelli. 2.ed. Rio de Janeiro: Jorge Zahar Editor, 2004. 
GOFFMAN, Erving. A ordem social e a interação. In: WINKIN, Yves (Org.). Os momentos e os seus homens: textos escolhidos e apresentados por Yves Winkin. Lisboa: Relógio d'Água, 1999. p. 99-107.

. Frame analysis. an essay on the organization of experience. Cambridge: Harvard University, 1974.

HARTOG, François. Uma retórica da alteridade. In: o espelho de Heródoto: ensaio sobre a representação do outro. Belo Horizonte: UFMG, 1999. p. 229-271.

LAG0, Cláudia. Ensinamentos antropológicos: a possibilidade de apreensão do outro no Jornalismo.

Revista Brazilian Journalism Research. v. 6, n. 1, p.164-178, 2010. Disponível em: <www.sbpjor.org.br/ bjr/article/view/253>. Acesso em: $10 \mathrm{dez} .2012$.

LANDOWSKI, Eric. Presenças do outro. São Paulo: Perspectiva, 2002.

LOPES, José de Souza. Poderá ainda o 0cidente escutar a voz que vem da África? In: AMÂNCIO, Iris (Org.). África-Brasil-África: matrizes, heranças e diálogos contemporâneos. Belo Horizonte: Editora PucMinas, 2008. p. 27-38.

MAIA, Marta R. A história oral como recurso metodológico na entrevista jornalística. In:

Contracampo - Revista do Programa de Pósgraduação em Comunicação. Niterói: Instituto de Arte e Comunicação Social da UFF, v.18, p.137-150, 2006. Disponível em: http://www.martamaia.pro.br/ pesquisas_historal.asp\#topo. Acesso em:

10 dez. 2012

MEDINA, Cremilda de Araújo. Entrevista, um diálogo possível. São Paulo: Ática, 2002.

MORIN, Edgar. A entrevista nas Ciências Sociais, na rádio e na televisão. In: MOLES, Abraham. Linguagem da cultura de massa. Petrópolis, RJ: Vozes, 1973. p.115-135.
RESENDE, Fernando. A narratividade do discurso jornalístico: a questão do outro. Revista Rumores

Research, n. 6, v. 1, set./dez. 2009. Disponível em: www. revistas.univerciencia.org/index.php/rumores/.../6799.

Acesso em: 10 dez. 2012

. 0 olhar às avessas: a lógica do texto jornalístico. 239 f. 2002. Tese (Doutorado em Comunicação Social) - Escola de Comunicação e Artes, Universidade de São Paulo, São Paulo, 2002.

ROÜCHOU, Joëlle. Ouvir o outro: entrevista na história oral e no jornalismo. In: CONGRESSO DA INTERCOM. 26., 2003. Belo Horizonte. Anais ... Belo Horizonte: Intercom, 2003. 13p. Disponível em: http://galaxy. intercom.org.br:8180/dspace/bitstream/1904/4421/1/ NP2ROUCHOU.pdf.

SAID, Edward. Orientalismo: 0 Oriente como invenção do Ocidente. São Paulo: Companhia das Letras, 1990.

SANTHIAG0, Ricardo. Esboço para um diálogo: história oral e jornalismo de grande extensão. Revista PJ: BR Jornalismo Brasileiro. São Paulo, Ano V, n. 8, jul. 2007. Disponível em: < http://www. eca.usp.br/pjbr/arquivos/artigos8_d.htm $>$. Acesso em: 10 dez. 2012.

SILVA, Mirian Chrystus Mello e. À sombra de Heródoto: a linhagem narrativa das matérias edificantes do Jornal Nacional. 151 f. 2002. Dissertação (Mestrado em Comunicação Social) - Faculdade de Filosofia e Ciências Humanas, Universidade Federal de Minas Gerais, Belo Horizonte, 2002.

SUSSEKIND, Flora. 0 Brasil não e longe daqui: 0 narrador, a viagem. São Paulo: Companhia das Letras, 1990.

VERÓN, Eliseo. Fragmentos de um tecido. São Leopoldo: UNISINOS, 2004.

WAGNER, Roy. A invenção da cultura. São Paulo: Cosac Naify, 2010. 


\section{Between two worlds: an encounter with the other in the process of journalism production}

\section{Abstract}

Media scenario is seen as an outstanding place where symbolic exchange of ideas and the sharing of meaning occur in the contemporary society. The journalistic craft, as a discursive practice implied in this scenario, conects us to a variety of ethnics and cultures, creating narratives and figures of otherness. In this sense, the main point of this research is to think about the relations that are developed with otherness within journalistic production. For that, we studied Nova Africa, a journalistic series aired by TV Brasil. Based on this series, we came to realize the intervention of the interviewees in the construction of meaning in it. By analysing the interaction of the interviewees in the series, we asked ourselves if journalism as a practice can gather and reflect the other when talking about him.

\section{Keywords}

Otherness. Journalism. Intercultural dialogue.

\section{Entre dos mundos: un encuentro con el otro en el proceso de producción periodística}

\section{Resumen}

El espacio de los medios de comunicación se constituye como escenario privilegiado del intercambio simbólico y de la construcción de significados en la sociedad contemporánea. La actividad periodística, una de las prácticas discursivas que forma este espacio, nos pone en contacto con diferentes personas y culturas, configurando relatos sobre la otredad. Nuestro trabajo elige estas narrativas como objeto de investigación, con el propósito de pensar la relación que el proceso de producción del periodismo desarrolla con la diferencia. Hemos trabajado una serie de reportajes intitulada Nueva África (del original en portugués: Nova África), vehiculada en el canal TV Brasil; ahí tratando de comprender la dinámica que se establece durante la constitución de sentidos de la serie, sobre todo en respecto a la relación entre la contribución de los entrevistados y la enunciación periodística. Al observar la participación de los entrevistados, la cuestión que nos motivó era si el periodismo puede realmente dar cuenta de las marcas del otro cuando habla de ello.

\section{Palabras-clave}

Otredad. Periodismo. Diálogo intercultural. 


\section{Expediente}

A revista E-Compós é a publicação científica em formato eletrônico da Associação Nacional dos Programas de Pós-Graduação em Comunicação (Compós). Lançada em 2004, tem como principal finalidade difundir a produção acadêmica de pesquisadores da área de Comunicação, inseridos em instituições do Brasil e do exterior.
E-COMPÓS I www.e-compos.org.br I E-ISSN 1808-2599

Revista da Associação Nacional dos Programas

de Pós-Graduação em Comunicação.

E-compós, Brasilia, v.16, n.1, jan./abr. 2013

A identificação das edições, a partir de 2008,

passa a ser volume anual com três números.

\section{CONSELHO EDITORIAL}

Afonso Albuquerque, Universidade Federal Fluminense, Brasil Alberto Carlos Augusto Klein, Universidade Estadual de Londrina, Brasil Álvaro Larangeira, Universidade Tuiuti do Paraná, Brasil André Luiz Martins Lemos, Universidade Federal da Bahia, Brasil Ângela Freire Prysthon, Universidade Federal de Pernambuco, Brasil Angela Cristina Salgueiro Marques, Faculdade Cásper Líbero (São Paulo), Brasil Antonio Roberto Chiachiri Filho, Faculdade Cásper Líbero, Brasil Arthur Autran Franco de Sá Neto, Universidade Federal de São Carlos, Brasil Benjamim Picado, Universidade Federal Fluminense, Brasil César Geraldo Guimarães, Universidade Federal de Minas Gerais, Brasil Cristiane Freitas Gutfreind, Pontifícia Universidade Católica do Rio Grande do Sul, Brasil

Denilson Lopes, Universidade Federal do Rio de Janeiro, Brasil Eduardo Peñuela Cañizal, Universidade Paulista, Brasil

Eduardo Vicente, Universidade de São Paulo, Brasil Eneus Trindade, Universidade de São Paulo, Brasil Erick Felinto de Oliveira, Universidade do Estado do Rio de Janeiro, Brasil Florence Dravet, Universidade Católica de Brasília, Brasil Gelson Santana, Universidade Anhembi/Morumbi, Brasil Gislene da Silva, Universidade Federal de Santa Catarina, Brasil Guillermo Orozco Gómez, Universidad de Guadalajara Gustavo Daudt Fischer, Universidade do Vale do Rio dos Sinos, Brasil Hector Ospina, Universidad de Manizales, Colômbia Herom Vargas, Universidade Municipal de São Caetano do Sul, Brasil Inês Vitorino, Universidade Federal do Ceará, Brasil Jay David Bolter, Georgia Institute of Technology Jeder Silveira Janotti Junior, Universidade Federal de Pernambuco, Brasil John DH Downing, University of Texas at Austin, Estados Unidos José Afonso da Silva Junior, Universidade Federal de Pernambuco, Brasil José Carlos Rodrigues, Pontifícia Universidade Católica do Rio de Janeiro, Brasil José Luiz Aidar Prado, Pontifícia Universidade Católica de São Paulo, Brasil Kelly Cristina de Souza Prudêncio, Universidade Federal do Paraná, Brasil.
Laan Mendes Barros, Universidade Metodista de São Paulo, Brasil Lance Strate, Fordham University, USA, Estados Unidos Lorraine Leu, University of Bristol, Grã-Bretanha Lucia Leão, Pontifícia Universidade Católica de São Paulo, Brasil Malena Segura Contrera, Universidade Paulista, Brasil

Márcio de Vasconcellos Serelle, Pontifícia Universidade Católica de Minas Gerais, Brasil

Maria Aparecida Baccega, Universidade de São Paulo e Escola Superior de Propaganda e Marketing, Brasil

Maria Ataide Malcher, Universidade Federal do Pará, Brasil

Maria das Graças Pinto Coelho, Universidade Federal do Rio Grande do Norte, Brasil Maria Immacolata Vassallo de Lopes, Universidade de São Paulo, Brasil Maria Luiza Martins de Mendonça, Universidade Federal de Goiás, Brasil Mauro de Souza Ventura, Universidade Estadual Paulista, Brasil Mauro Pereira Porto, Tulane University, Estados Unidos Mirna Feitoza Pereira, Universidade Federal do Amazonas, Brasil Nilda Aparecida Jacks, Universidade Federal do Rio Grande do Sul, Brasil Osvando J. de Morais, Universidade de Sorocaba, Brasil Potiguara Mendes Silveira Jr, Universidade Federal de Juiz de Fora, Brasil Renato Cordeiro Gomes, Pontifícia Universidade Católica do Rio de Janeiro, Brasil Robert K Logan, University of Toronto, Canadá

Ronaldo George Helal, Universidade do Estado do Rio de Janeiro, Brasil Rose Melo Rocha, Escola Superior de Propaganda e Marketing, Brasil Rossana Reguillo, Instituto de Estudos Superiores do Ocidente, Mexico Rousiley Celi Moreira Maia, Universidade Federal de Minas Gerais, Brasil Sebastião Guilherme Albano da Costa, Universidade Federal do Rio Grande do Norte, Brasil

Simone Maria Andrade Pereira de Sá, Universidade Federal Fluminense, Brasil Tiago Quiroga Fausto Neto, Universidade de Brasília, Brasil Suzete Venturelli, Universidade de Brasília, Brasil Valerio Fuenzalida Fernández, Puc-Chile, Chile

Veneza Mayora Ronsini, Universidade Federal de Santa Maria, Brasil Vera Regina Veiga França, Universidade Federal de Minas Gerais, Brasil

\section{COMISSÃO EDITORIAL}

Adriana Braga I Pontifícia Universidade Católica do Rio de Janeiro, Brasil

Felipe Costa Trotta I Universidade Federal Fluminense, Brasil

CONSULTORES AD HOC

Bruno Campanella, Universidade Federal Fluminense, Brasil

Christa Berger, Universidade do Vale do Rio dos Sinos, Brasil

Edison Gastaldo, Universidade Federal Rural do Rio de Janeiro, Brasil

José Luiz Braga, Universidade do Vale do Rio dos Sinos, Brasil

\section{EDIÇÃO DE TEXTO E RESUMOS I Susane Barros}

SECRETÁRIA EXECUTIVA I Juliana Depiné

EDITORACã̃ ELETRÔNICA I Roka Estúdio
COMPóS I www.compos.org.br

Associação Nacional dos Programas de Pós-Graduação em Comunicação

Presidente

Julio Pinto

Pontifícia Universidade Católica de Minas Gerais, Brasil juliopinto@pucminas.br

Vice-presidente

Itania Maria Mota Gomes

Universidade Federal da Bahia, Brasil

itania@ufba.br

Secretária-Geral

Inês Vitorino

Universidade Federal do Ceará, Brasil

inesvic@gmail.com 